\title{
Locusts and People: Integrating the Social Sciences in Sustainable Locust Management
}

\author{
Clara Therville ${ }^{1, *(\mathbb{D}}$, John M. Anderies ${ }^{1,2} \mathbb{D}$, Michel Lecoq $^{3} \mathbb{D}$ and Arianne Cease ${ }^{1,4}$ \\ 1 School of Sustainability, Arizona State University, Tempe, AZ 85287, USA; m.anderies@asu.edu (J.M.A.); \\ acease@asu.edu (A.C.) \\ 2 School of Human Evolution and Social Change, Arizona State University, Tempe, AZ 85287, USA \\ 3 CIRAD, UMR CBGP, F-34398 Montpellier, France; mlecoq34@gmail.com \\ 4 School of Life Sciences, Arizona State University, Tempe, AZ 85287, USA \\ * Correspondence: clara.therville@gmail.com; Tel.: +33-6-7959-9705
}

Citation: Therville, C.; Anderies, J.M.; Lecoq, M.; Cease, A. Locusts and People: Integrating the Social Sciences in Sustainable Locust Management. Agronomy 2021, 11, 951 . https://doi.org/10.3390/ agronomy11050951

\section{Academic Editor:}

Nikolaos Papadopoulos

Received: 18 April 2021

Accepted: 7 May 2021

Published: 12 May 2021

Publisher's Note: MDPI stays neutral with regard to jurisdictional claims in published maps and institutional affiliations.

Copyright: (c) 2021 by the authors. Licensee MDPI, Basel, Switzerland. This article is an open access article distributed under the terms and conditions of the Creative Commons Attribution (CC BY) license (https:/ / creativecommons.org/licenses/by/ $4.0 /$ )

\begin{abstract}
Locust outbreaks have impacted agricultural societies for millennia, they persist today, and humans aim to manage them using preventative strategies. While locusts have been a focus for natural sciences for more than a century, social sciences remain largely underrepresented. Yet, organizational, economic, and cultural variables substantially impact these management strategies. The social sciences are one important means through which researchers and practitioners can better understand these issues. This paper examines the scope and purpose of different subfields of social science and explores how they can be applied to different issues faced by entomologists and practitioners to implement sustainable locust research and management. In particular, we discuss how environmental governance studies resonate with two major challenges faced by locust managers: implementing a preventative strategy over a large spatial scale and managing an intermittent outbreak dynamic characterized by periods of recession and absence of the threat. We contend that the social sciences can help facilitate locust management policies, actions and outcomes that are more legitimate, salient, robust, and effective.
\end{abstract}

Keywords: environmental governance; social variables; locusts; social sciences

\section{Locust Science Needs Social Sciences}

It is evident to all researchers and practitioners concerned by locusts that these insects have always been of great concern to people socially, culturally, economically, and politically. Locusts are currently considered by the FAO as "one of the most destructive migratory pests in the world"(http:/ / www.fao.org/locusts/en/, accessed on 10 May 2021): there are at least 20 different agriculturally important locust species affecting the economies of most continents, a large range of more or less developed countries, and the livelihoods of millions during outbreaks [1,2]. In addition to impacting vulnerable agricultural communities in the short term, a locust plague can have long-term consequences such as spurring migration to urban areas, decreased access to education for children, exacerbating tensions between pastoralists and farmers, and overexploitation of natural resources [3,4]. Control campaigns can cost many millions of dollars [5], and the chemical insecticides used can have serious side effects on human health and the environment [6,7]. Locusts are also an object of political power. For example, Peloquin (2013) demonstrated how the French colonial empire designed the management of the desert locust crisis in 1943 to be perceived as a transnational and constructive federation against a common enemy (locusts), but in ways that strengthened its authority during a geopolitical legitimacy crisis [8].

Throughout history, humans have predominantly considered locusts as a threat and have tried to protect themselves from them. Until about the last one hundred years, locusts were described as literally falling from the sky and anticipating invasions was impossible [9]. The urgency to find solutions to this agricultural challenge led governments 
to support scientific research, locust ecology in particular, to locate main breeding areas (outbreak areas) and develop more efficient survey and control methods [10]. It was the discovery by Uvarov of locust phase polyphenism [11,12] that directed field research towards locating outbreak areas from the 1930s, and thus provided a rationale for preventive strategies around the world [10]. This discovery induced a paradigm shift from old reactive approaches focusing on crop protection in a context of complete uncertainty to anticipative preventive strategies and risk management systems [13-15]. Many entomologists around the world thus devoted their careers to exploring the best potential biological and ecological solutions to deal with the locust problem [10]. Since then, tremendous scientific work, especially in the natural sciences, as well as technological advances for example in communication, remote sensing imagery and climatic and weather data collection were developed to manage locusts $[13,14]$. The current preventive strategy relies on the surveillance of areas prone to producing gregarious populations, which ultimately help people make decisions for control according to locust densities and location of infestations, using either chemical, biological or ecological control $[13,14]$. However, this strategy remains questioned, as illustrated by the debate that followed the 2003-2005 desert locust invasion $[16,17]$. Locust outbreaks continue to arise and some authors wonder if sustainable locust management is possible [18].

This observation has led some scientists and practitioners to insist on the social and organizational variables that may impact locust management [19]. Research has described this impact on our capacity to understand and manage locusts since the end of the 19th century for different locust species in different part of the world (see, e.g., $[10,20])$. These studies point out the social constraints to maintaining an efficient preventive strategy through time and through large spatial scales. Recent reviews highlight a common and significant constraint for sustainable locust management: the reduction of resources during recession times [14]. As one of the most well-known species, the case of the desert locust provides old testimonies of this challenge. Roy, an historical expert in the fight against locust invasions in West Africa, looked back at the conditions that made the great invasion of 1987-1989 possible through the degradation of an existing preventive control strategy [21]. He highlights the impact of the loss of knowledge during recession times, induced by the dismissal or retirement of field staff and researchers. Past and current outbreaks of the desert locust have also been explained by armed conflicts and insecurity that have led some countries to lack capacity to sustain expertise, monitoring, and control [22,23]. In 2005, Lecoq insisted on the need for stronger risk-management systems, and put an emphasis on governance, funding, flexibility and a better understanding of the role of locust-control stakeholders [19]. Fifteen years later, the identified highest priorities to face desert locust outbreaks sounds familiar [22]: "(a) to ensure that the political and socio-economic conditions are in place so that vulnerable human populations can adapt to new large-scale threats and (b) to maintain a culture of long-term risk assessment with constant necessary means".

The social sciences are one means through which researchers and practitioners could come to understand the social variables that impact locust management. However, paradoxically, while locust management is seriously constrained by organizational, economic, and coordination issues [14], social sciences are underused in locust research. There are numerous recent studies on locust biology and on the use of remote sensing technologies to improve locust management systems (reviewed in Cullen et al. 2017) [24]. We do not question the fact that further research is needed on genetics, ecology, population dynamics, or remote sensing to improve our knowledge of locusts and management strategies, especially under a changing climate. However, more than fifteen years after the call to switch locust management "from ecology to anthropology" [19], social sciences are still overlooked in locust studies. That being said, counter-examples can be found. For instance, economics has already provided useful arguments to defend preventive strategies for locusts. In the case of the Australian plague locust [25], the benefit-cost ratio for all the control campaigns of the 2010-2011 plague is estimated at 19:1, indicating that every dollar invested in locust control generates $\$ 19$ in avoided losses. 
This call towards social sciences also meets other calls towards the reframing of risk management, crop pest management, insect science, and locust management in particular, using social-ecological, sustainability, and transdisciplinary approaches [26-28]. A socialecological approach is a way to emphasize the interlinked social and ecological dynamics and the cross-scale and cross-level social-ecological complexity involved in managing the environment [29,30]. For example, Cease et al. [31] described the locust-grassland-human system as a coupled human and natural system, implying complex feedback that connect geographically distinct people and places across time (ecological connections with locust migration or socio-economic connections through markets). Considering locusts as a "wicked" problem [32] also induces new ways of doing science, capable of dealing with problems characterized by high stakes, uncertainties, values in dispute, and urgent decisions [33]. In such a renewed frame, research not only has to be scientifically robust, but should also be more involved in the resolution of societal problems and promote the participation of civil society. This requirement justifies an extension of the peer community involved in the resolution of environmental problems, including social scientists, and the mobilization of both interdisciplinarity (within academia but across disciplinary boundaries) and transdisciplinarity-also referred to as cross-sectoral (across the professional boundaries between researchers and practitioners, including managers and agriculturists in this case) [34].

In response to calls to make social sciences mainstream in locust research and management, this paper provides a succinct guide and overview of the social sciences for present and future locust managers, for natural scientists leading or participating in multistakeholder processes and interested in strengthening the role of social sciences, and for social scientists interested in locust research. We consider that the failure of social science to be mainstreamed stems in part from a lack of clearly articulated objectives and values associated with the social sciences. This article firstly identifies the distinct contributions that different fields of the social sciences can make to understanding and improving locust management. Then, we detail the main social challenges faced in locust management and how different areas of social science can shed light on them. In particular, we mention other examples of risk studies (e.g., shocks such as earthquakes or floods), institutional approaches used in these cases, and advancements surrounding the resilience of complex social-ecological systems. We conclude with a discussion of several key considerations for better engaging with the social sciences to improve locust management.

\section{What Are the Social Sciences?}

The social sciences are a set of tools and ideas that focus on how humans make decisions, create and maintain social relations, and how these individual processes lead to macro-level patterns of organization, such as interest groups, cultures, or nation states. Locust management involves decisions of individual farmers, managers, and policy actors, as well as the relationships among these actors (e.g., information exchange, coordination of activities). These decisions and relationships lead to macrolevel patterns (e.g., organizations to manage locust outbreaks across the spatio-temporal expanse of locust outbreaks). Thus, social science is a useful tool to understand the human and social dimensions of environmental issues in general [35], and of locust management in particular. Yet their absence is commonly reported in environmental studies, either dealing with global environmental change research [36], biodiversity conservation [35], or pest management [26,37]. This can be observed in the locust community through the limited number of social scientists participating in locust symposia and in locust review papers [24]. The barriers impacting the integration of social sciences and natural sciences has been particularly explored in the field of conservation sciences [38,39]. These papers highlight how, among many natural scientists and practitioners, there remains a lack of awareness about the social sciences. This knowledge void interferes with the ability to engage with the social sciences in a constructive manner that can inform management practices $[35,40]$. The multiple challenges that are known to interfere with the integration can be conceptual (e.g., 
confusion over the role of social sciences, different expectations, and/or disagreements on frameworks, definitions or concepts) or structural (e.g., lack of social scientists, compartmentalized organization, and/or lack of funding or opportunities for interdisciplinary collaborations) $[38,41]$. Another common challenge is the instrumentalization of social scientists to better package or market ecological knowledge [38], that devalues the knowledge they produce. Conversely, the critical approach developed by some social scientists on the "politics of nature", highlighting the role of ecology in power relations and injustices [39], has led to misunderstandings and even to a mistrust between social and natural scientists. Resolving these challenges requires a mutual respect and a basic understanding of respective approaches: both social and natural scientists should be able to identify the different disciplines embedded in the other realm, and be aware of the philosophical principles and theoretical assumptions of each of these disciplines [42]. On the other hand, each scientist should be able to make their discipline more digestible for scientists originating from other disciplines, through a more straightforward use of language, direct communication and accessibility of research findings [39].

Without going into detail-see Moon and Blackman [42] or Bennett et al. [35] for a more complete understanding of the social sciences-we provide here some elements of social science ideas and theory relevant to locust management. Social sciences are used to study five broad categories of the social realm: (i) social phenomena (e.g., markets, governance, politics, culture, demographics), (ii) social practices and processes (e.g., social organization, decision-making, knowledge exchange, collaboration), (iii) social attributes (e.g., social capital, trust, memory), (iv) actors, roles, and positions (e.g., bridging organizations, leadership), or (v) individual attributes (e.g., values, beliefs, knowledge, motivations, preferences, behaviors) $[35,43]$. They include disciplines such as sociology, anthropology, political science, geography, economics, history, psychology, and other more applied social sciences such as education, development, or communication science. Each discipline has specific topical strengths (e.g., governance for political science, social interactions and social facts for sociology, communication science to inform communication strategies during a crisis) and relies on established and specific bodies of social theories. Specific disciplines of the social sciences have included environmental concerns, such as environmental psychology or environmental economics. To tackle complex social-ecological problems, multiple interdisciplinary fields have emerged as well such as the resilience of social-ecological systems [29], environmental social science [44], political ecology [45] or environmental humanities [46]. All of them highlight the interconnectedness between the biophysical and the social and are supposed to facilitate the engagement between natural and social scientists.

Social sciences can be conducted on issues at different scales, from individual to local to global. The individual scale might be adopted to study perceptions, attitudes, or behaviors. For example, what are the preferences of farmers regarding the use of insecticides [47]? At the global scale, scientists might study governance models and the impact of decentralization in locust control [48]. The applications of social sciences vary from predicting, understanding, emancipating, or deconstructing the issue of interest [42]. They can focus on understanding social phenomena, testing or developing theories, and/or giving critical insights on a situation to overcome injustices. More applied social science fields such as communication science can help to think about the role played by information and communication technologies to promote coordination and appropriate responses in the face of extreme events [49], e.g., locust plagues. Methodology can be qualitative (e.g., interviews, focus groups, discourse analysis), quantitative (e.g., closed-ended questionnaires, cost-benefit analysis), participatory (e.g., participatory action research, photovoice), and/or forward-thinking (e.g., scenario planning, economic modeling) [35]. Alongside this "social science" panel, the arts and humanities, which designate knowledge fields related to culture in general (including history, philosophy, cultural and science studies or literature) should also be mentioned as an important complement to both social sciences and natural sciences. They question our values, our representations, our responsibilities [46], and provide sensitive means to address these fundamental issues. 


\section{An Overview of Existing Social Science Contributions to Locust Management}

Although poorly represented, social sciences are not completely absent from the locust research and management world and some contributions can be found. They can be differentiated depending on their disciplinary approach and on their applications, from more analytical to more applied (Figure 1). Figure 1 is an attempt to summarize these distinctions and highlight some of the major contributions of the social sciences applied to locust management. The proposed categories are not necessarily exclusive from one another, nor as clear as they appear in Figure 1 since this should rather be seen as a continuum.

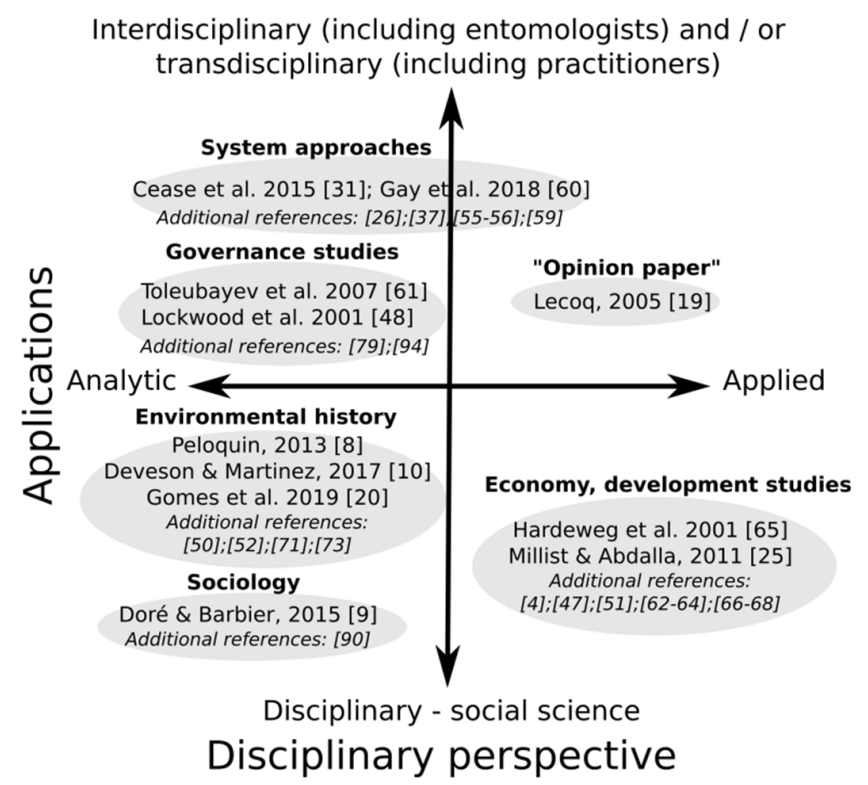

Figure 1. A framework to summarize some of the main types of studies in locust science that include social sciences, depending on their disciplinary approach and on their applications, from more analytical to more applied. In additional references, some papers may not focus on locusts but are representative of a given approach, e.g., [50].

Diverse disciplinary approaches can be found in the social science literature on locusts: contributions can be embedded in one subdiscipline of the social sciences, such as sociology [9] or economics [25]; they can emerge from social science fields that are specifically interested in environmental issues, such as environmental history [10] or political ecology [51]; finally, they can come from interdisciplinary and transdisciplinary groups of authors who are willing to address the social variables impacting locust management $[31,48]$. Such papers may involve both entomologists/natural scientists alongside social scientists (interdisciplinary approach) and practitioners (transdisciplinary approach) who sometimes have a strong interest in social sciences and can even be double-hatted at the same time, being a practitioner or entomologist and trained as a social scientist. These contributions also reflect diverse possible applications: while some of them aim to describe and understand social phenomenon from an analytical point of view [9], others are clearly oriented towards action: they urge some changes in the ways we are thinking, managing and governing locusts outbreaks $[19,48]$, are assessing the economic feasibility of current management strategies [25] or are exploring the possibility to use renewed instruments in locust management, such as payments for ecosystem services [52] or compensation funds [47].

Along this framework (Figure 1), four main categories of studies can be identified. First, studies embedded in an analytical approach and rooted in classical fields of the social sciences such as sociology or history can be found in the lower left corner. Interestingly, history is a particularly well represented discipline with contributions focusing on the desert locust [8], the South American locust [10], the Australian plague locust [53] and the 
Moroccan locust [20]. These studies can focus on a specific event in history, such as the 1943 conference convened to discuss ongoing locust plagues in Northwestern Africa [8], or retrace a longer history of structuration of locust management of over 50 years $[10,20]$. Lessons learned include perspectives on historical distributions of locust invasions, explanations regarding the ineffectiveness of the measures taken, including a lack of transboundary coordination [20], or the strong interactions between political power and scientific research, leading entomologists to be recognized as public scientists [10]. By learning lessons from the past, environmental history offers enormous potential to inform contemporary locust management. According to Gomes et al. [20], histories can help to change the world and "Neglecting the history of locusts [...] is a step towards forgetting the presence of the species...", which is a key concern in locust management, as we will discuss later.

Second, studies located in the upper left corner of the figure were written by interdisciplinary and transdisciplinary groups of authors, even if they were still embedded in a particular analytical perspective. This includes what we have called social-ecological systems or "SES" approaches, which draw on theory from ecology, economics, and political science to focus on understanding the complex dynamics generated by multi-level interactions (interactions on multiple temporal and spatial scales linked across different levels of social organization) between inter-related social and ecological systems. These studies have been strongly influenced by systems theory and resilience studies and used concepts such as coupled human and natural systems, telecoupling, scales and scale mismatch, feedback loops or complex adaptive systems $[30,54,55]$ to discuss the complex, and sometimes long-distance social-ecological interactions within the locust system. Ecologists can be pushed towards such an approach when studying the interactions between locusts and their environment, which thus includes the impact of human practices (crop farming, grazing) on the surrounding environment. For example, Cease et al. [31], Le Gall et al. [56], Word et al. [57] and others before them [58,59], demonstrated there can be a substantial impact of overgrazing or the type of crops and soil management regime on locust dynamics. This opens a space for discussion to include land management practices as a way to manage locusts, and thus to include farmers and their social environment (e.g., markets, policies) as key players. Within this family of systems studies, Gay et al. [60,61] focus on the ability of the current preventive system to manage desert locust plagues. Using multi-agent systems that include both human (e.g., field teams, national control units, funding institutions) and non-human agents (e.g., locusts), they explore the role of funding institutions' awareness, budget cyclicity, and the lack of access to some areas due to insecurity. This last topic has also been recently explored by Showler and Lecoq [23] who demonstrated the various effects of armed conflicts in the case of the desert locust over the last 35 years. Lastly, some studies develop a particular interest for collective action and governance in general. For example, Toleubayev et al. [62] focuses on the locust management system in Kazakhstan since the formation of the Soviet State and its disintegration after the collapse of the Soviet Union. Similarly, Lockwood et al. [48] analyzed the relative importance of various stakeholders and interests in three case studies (Wyoming in the United States, Eritrea, and Irkutsk in Russia). They observed the changing role of central governments with the deployment of bottom-up approaches and decentralization, and the consequences of locust plagues for farmers in different contexts. From these observations, the authors questioned the historical dependence on distant governments. In the same vein, in the upper right corner of Figure 1, Lecoq [19] proposed what we identify as an opinion paper, which suggested that "a new approach to locust issues (...) using techniques derived from sociological and anthropological sciences" is needed. After retracing the history of recent desert locust plagues, Lecoq acknowledged the role played by organizational problems and by the lack of involvement in prevention systems of various stakeholders such as farmers' organizations: "the locust is no longer the real problem, humans are the real problem. Every time there has been an outbreak over the last 50 years, the main problem has been human organization...". He thus called towards the development of a risk management system, a new governance strategy involving a larger panel of stakeholders, and a better understanding of the role of each of them. 
Studies in the lower right corner of Figure 1 used a disciplinary approach, mostly rooted in economic or in socio-economic and development studies with the practical objective of evaluating current management practices and proposing credible alternatives where appropriate. In particular, desert locust campaigns have been submitted to socio-economic evaluations under the impetus of the FAO in the 1990s [63]. These studies aimed to identify who is affected by the desert locust and to what extent, if the current management strategy and control campaigns are appropriate, and what are the costs and the other possible policy responses. Such studies are recognized to be difficult to carry out because of the enormous area that must be studied, the heterogeneity of the potential damages of the pest, the multiple variables that can impact crop production, and the irregular occurrence of outbreaks [64]. Some initial studies criticized the effectiveness of control strategies which are presented as not very cost effective economically, socially, or environmentally [64,65]. Complementary studies were developed later to better integrate the stakes and perceptions of diverse groups at the farm and households levels, and proposed alternatives such as compensation, insurance policies, farmers' adaptation strategies or biological control [47,66-68]. Lastly, some recent studies demonstrated the long term impact of locust plagues, in particular on health and education, and the lasting damages the plagues caused during early childhood into adulthood [4,69].

To conclude, social science studies interested in locusts are as diverse as natural science studies [24]. As illustrated in Figure 2, they are included in a diversity of approaches (e.g., environmental history, systems approach, sociology, economics, and development studies). They mobilize a diversity of methodologies (e.g., document analysis, quantitative data analysis, economic evaluation, ethnographic approach, reliance on expertise knowledge). They can pursue different objectives, from policy function and structure or efficiency analysis to the inclusion of people's perceptions and social-ecological analysis. They can focus on different scales, from individuals to nations and beyond, they can support existing management practices or adopt a critical approach and try to push towards alternative solutions. While some disciplines are particularly well represented, such as environmental history or economics, others are less so, such as communication, philosophy, sociology, anthropology, and psychology. Their inputs could be valuable to locust science in questioning ethics and epistemologies (see, e.g., the recent work of Lockwood and Sardo [70]), or in observing the issues in the day-to-day management of locusts, during crisis and recession times. For example, communication science could contribute to the development of communication plans to ensure trust over the long run and support coordination during outbreaks.

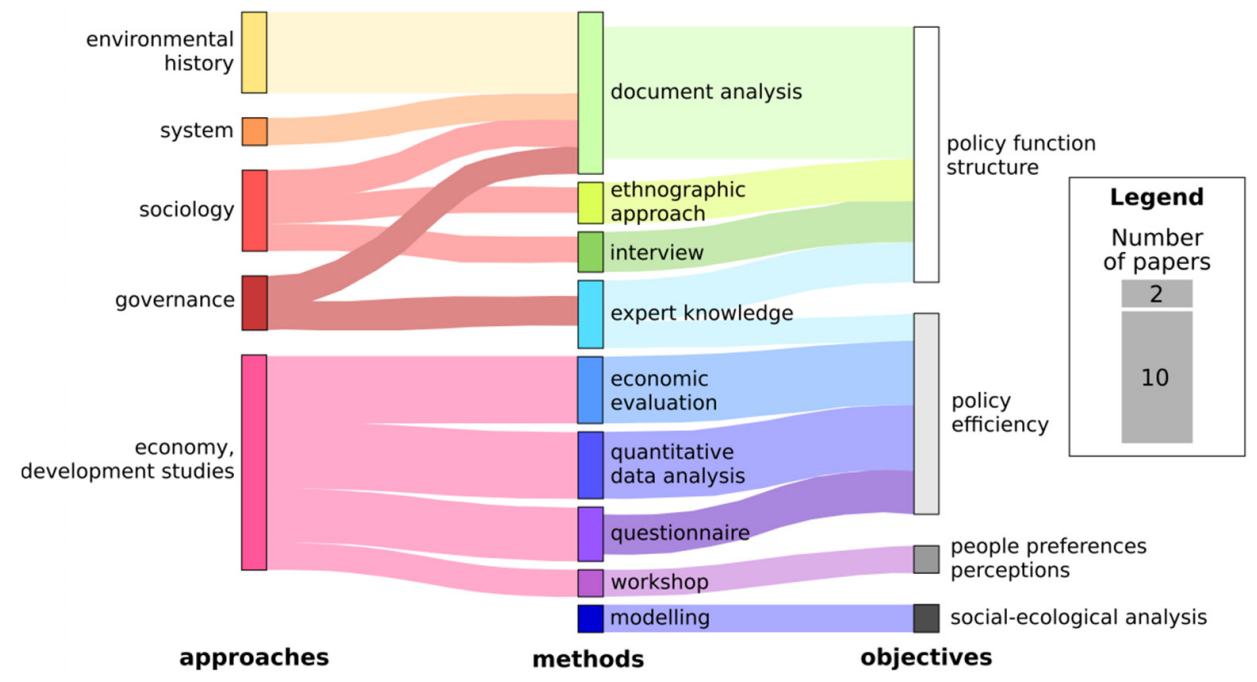

Figure 2. Main approaches, methodologies and objectives represented in the studies included in Figure 1 and specifically focusing on locusts $(n=25)$. Only the boxes and flows represented in two or more papers are represented on this figure. The flows on the left represent which methods are used 
by each approach. The flows on the right represent which methods are used to pursue the different objectives. The size of the flows is proportional to the number of papers using this represented flow. For more detail, see Table S1.

\section{Social Sciences and Tackling Locust Management Challenges}

In this section, we highlight how social sciences can help to tackle two of the main challenges of locust management: (1) ensuring coordination and a multi-level governance structure from a local to a very large scale, and (2) maintaining the management system during recession times.

\subsection{Ensuring Multi-Level and Large-Scale Coordination}

Most countries recognize that effective locust management requires some form of large scale coordination because control programs are beyond the capabilities of individual landholders alone [14]. At a landscape scale, locusts readily move from one farm to another, so their treatment is often considered a community responsibility. Cooperation at a local scale can be implemented more or less informally or formally, for example informally at a village/town scale or formally through cooperative programs at the county or state level, as in Wyoming, USA [37]. Combating locust outbreaks has also led governments to take responsibility since the latter part of the 1800s, as is the case in Australia or in Argentina [10], or the US in response to the Rocky Mountain locust outbreaks [71] that led to the emergence of some of the first national plant health policies [72].

For species such as the desert locust, which is associated with one of the most ancient organized preventive systems, the great mobility of the swarms imposes the necessity of bilateral, regional and international cooperation [73]. As illustrated by historical studies, some evidence from large-scale collective mobilization against locusts can already be found in Antiquity, with the existence of local locust control specialists and the use of armies to destroy the insects or help with the harvest [74]. The internationalization of the locust problem started as early as the beginning of the 20th century when a large plague in Algeria contributed to the awareness of the international community of the fight against the locust plague [50]. However, the first attempt to find a transboundary solution at a truly international scale only emerged in the 1920s with the first international conference on locust control held in Rome under the auspices of the International Institute for Agriculture and which resulted in an "International Convention for the control of locusts and grasshoppers" [75]. Since that time, it was considered as hopeless to study the locust problem on a narrow territorial basis and cooperation has not ceased to develop to the present day. Many efforts have been pursued to ensure better transboundary coordination. In the 1930s the process of formation of a locust scientific community and the institutionalization of the international scientific fight against the locust took place by means of five international locust conferences, held in Rome (1931), Paris (1932), London (1934), Cairo (1936) and Brussels (1938), resulting in a first conception of a preventive control program for a few locust species by regular monitoring of the outbreak areas [76]. Cooperation became a true reality in the 1950s, with the creation of the desert locust control committee (DLCC) under the aegis of the FAO in 1954, mandated by its Member States to ensure the coordination of monitoring and control activities of the desert locust [73]. Since the creation of the DLCC, FAO has continued to play an active role to promote international locust control cooperation, on the desert locust as well as for many other locust species (i.e., migratory, Moroccan, South American, and red locusts). In present days, the DLCC includes representatives from all the countries affected by the desert locust as well as those which take part in the locust control campaigns, such as various donor countries helping to finance control campaigns. The DLCC is linked in the field by three regional Commissions (created under the auspices of the FAO and at the request of the affected countries): the commission for the Western Area, CLCPRO (the "Commission de lutte contre le Criquet Pèlerin dans la Région Occidentale" created in 2002 to coordinate and finance a regional solidarity on both sides of the Sahel $[51,77,78])$, the Central Region (CRC), and the eastern region 
in Southwest Asia (SWAC), as well as by an inter-state organization: the Desert Locust Control Organization for Eastern Africa (DLCO-EA). These Commissions are mandated to promote all activities, research and training necessary to ensure effective preventive control and capacity to deal with any invasion of the desert locust [73]. However, coordination still presents some weaknesses, even if solidarity and mutual support are well established. In their evaluation of the 2003-2005 desert locust campaign for instance, Brader et al. note that " $A$ weakness is the lack of clarity concerning the different roles of different actors, and how these relate to each other" [3].

Given this context, a challenge that the social sciences can help to address is to understand if, when, and how collaboration is effective [79] from local to the international levels. Because of their mobility, locusts represent a collective action problem: they reveal a situation of mutual interdependence between the actors where outcomes depend on the actions of all of these actors. Invasive species, crop diseases, locusts, and other migratory pests have been considered by some authors as a "public bad" [62], a "collective bad" [80], or as a "public good" for their controlling system [81]. These terms all refer to collective action theory [82]. Many authors have noted that desert locust control should be considered as a regional or even international "public good" [83,84], meaning that it is provided as a service accessible to all, including vulnerable people, and supported by those who can afford it and are willing to pay for it, e.g., the general public through governments, donor countries or otherwise. As acknowledged by Toleubayev regarding this "common enemy" [62]: "agricultural producers are not able to control locusts outside their private plots. This is why many countries treat the control of migratory and highly destructive pests as a public service, comparable with emergency services such as the fire brigade and the police". Compared to other archetypal examples of commons such as small-scale forests or irrigation systems, locusts are special since they pose a problem that evades and exceeds the spatial reach and extent of control of the nation state. They thus raise transboundary governance issues as do bluefin tuna fisheries, another archetypal example used to study collective action in large-scale social-ecological systems [85,86]. These transboundary cases have a high number of stakeholders, the temporal and spatial extent of biophysical processes go beyond and are permeable to geopolitical boundaries, and there is often a limited understanding of the complexities of ecological and societal dynamics. Therefore, collective action and collaborative environmental governance are essential [79], which underscores the importance of stronger inclusion of collective action theories $[79,82]$ in the design of governance regimes. In particular, the notion of mismatch can be useful regarding locust governance. According to several authors, many of the problems encountered by societies in managing natural resources arise because of a mismatch between the scale of management and the scale of the ecological processes being managed [30,55,87]. This has been referred to as "scale mismatches", the "scale challenge", institutional "fit" or "interplay", a challenge which is particularly relevant for transboundary issues such as locusts.

Raising coordination issues and the scale challenge, including at a transnational level, is not new in studying locusts. For example, through an historical approach [20], Gomes et al. demonstrated that transnational collaboration was considered fundamental to fight against locusts since the beginning of the 20th century. Through the example of the Iberic peninsula, the authors highlighted the attempts and difficulties in implementing such a coordinationeffort. Conflicting interests and lack of means led the Spanish actors to blame each other for losses, and the Portuguese actors to blame the inaction of their Spanish neighbors as they observed locust swarms frequently travelling across the border. While a widespread opinion throughout the twentieth century was that Iberians should fight the locusts together, and some evidence support this idea of cooperation, Gomes et al. concluded that "cooperation and coordination were rare or non-existent". In a second example, Lockwood et al. [48], recognized that scale and scale mismatch are fundamental problems in assessing the sustainability of controlling locusts. By focusing on what they called the "geopolitical scale", the authors insisted on the problem of the historical dependence 
of local agents on distant governments that often have the resources, knowledge, and expertise. In parallel, the authors observed a paradoxical trend towards decentralization in locust control characterized by a decline in external support with the aim of increasing responsibilities at the local level. With the notions of "social scale" and "interest scale", they highlighted the diversity of motivations, gains, and losses in different contexts and at several governance levels, for example between farmers, the general public, agrochemical industries, and governments. In a final example, Peloquin [8,51] provided an example of a critical study regarding the concept of scale mismatch. Similar to other political ecologists, rather than taking the mismatch between institutions and ecosystems as given, he critically investigated why and how given socio-ecological dynamics become adopted as management mandates by agencies, and what particular technological or institutional arrangement is favored by these configurations. Taking the example of locusts, he illustrated how the French colonial Empire prioritized organizing against the desert locust during the Second World War because the spatial extent of the insect provided an ideal context in which to reinvent the spatiality and legitimacy of the French Empire as a transnational and constructive federation during a geopolitical crisis [8]. Similarly, Roy describes how the existence of two colonial empires on the African continent-French in the West, English in the East-explained for decades the lack of cooperation at the scale of the continent regarding the management of the desert locust [21].

\subsection{Maintaining Vigilance during Recession Times}

The second main challenge is to maintain the infrastructures needed for sustainable locust management during recession times. Locusts are temporal, alternating absence with peaks of high activity that must be rapidly managed. Major outbreaks can be separated by several decades, depending on the species and on the maintenance and efficiency through time of the management system. Such long-term environmental problems raise the issue of funding, support provision, and knowledge maintenance over substantial time frames [79]. For locust managers, an acknowledged challenge is the maintenance of an operational control system and a set of elements: (i) available and functional material for survey and control (e.g.,vehicles, planes, insecticides) and (ii) available and trained staff during recession times. Funding is of course essential to ensure the maintenance of these two crucial elements.

Some studies on locusts have tackled this issue. As illustrated in Figure 3, Lecoq was one of the first to explicitly refer to an institutional cyclicity in the case of locusts [88]. Making an analogy with locust phase polyphenism, he characterized an alternation between two institutional phases: a motivation phase associated with important funding in the face of an emergency situation, and an oblivion phase during recession times when "the memory of the invasion fades, funding is reduced below an operational level, specialists are dispersed, and motivation wanes". This "vicious" cycle [60] thus refer to a situation in which one is locked in a complex chains of events that reinforce themselves through a feedback loop and that has detrimental results. It is typified by the desert locust but can also be observed in Madagascar for the migratory locust [14] and in the South American locust [89]. When looking back at the desert locust invasion of 1987-1989 [21], Roy notes that when the severity of the threat diminished, vigilance is decreased. Under other constraints and faced with other emergencies, government authorities gradually considered locust control action a secondary interest. Funding from government partners was deferred, then reduced or even suspended, leading to a decrease in operational potential, staff and non-renewed equipment that degrades. Through an insidious process, managers worried about the possible loss of their positions and tended to hide the seriousness of the decline in field staff and resources from the government on which they depended. Roy described the loss of knowledge induced by the dismissal or retirement of field staff and researchers as "one of the most devastating effects (...) as equipment can be renewed and insecticide stocks replenished in a matter of months, but the loss of these experienced and dedicated field staff is an irretrievable loss-it will take many years to train their successors, but the trainers themselves have become 
scarce". Roy and Lecoq thus asked this question which remains topical [21,88]: how to get out of this vicious cycle? How can an operational structure be maintained against an intermittent scourge? We add this complementary question: how to identify emerging institutional weaknesses before they reveal themselves mostly during a time of crisis?

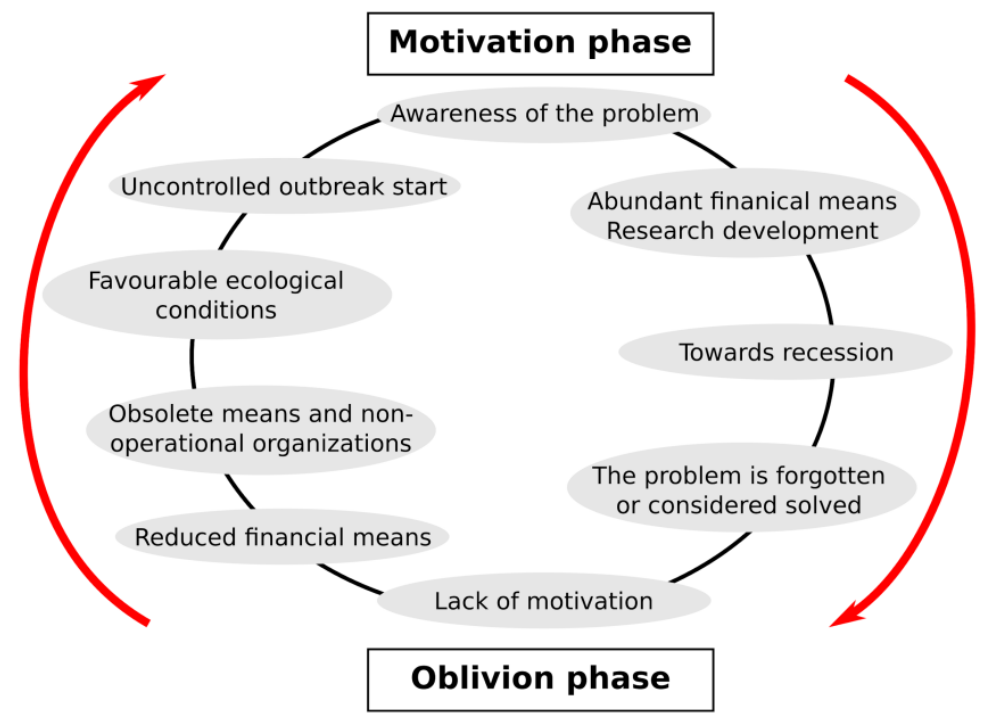

Figure 3. The phase theory applied to institutions: a representation of the vicious cycle alternating a motivation phase and an oblivion phase in locust management. Adapted from Lecoq, 1991 [88].

The French sociologist Doré and colleagues studied the maintenance of vigilance during recession times $[9,90]$. In a time when the efficiency of the preventive control system was questioned, their work was an attempt to understand the failures of the preventive system that led to the 2003-2005 desert locust invasion. More than a lack of trained human resources, Doré et al. highlighted the shortcomings of international involvement which, by seeking to rationalize expenditures, created a slow and under-mobilization of logistical and human resources. Bilateral and regional assistance mechanisms can mitigate these shortcomings to some extent. For example, the authors discussed the necessity to integrate the complexity of organizational and governance issues in a multi-level actor system, and to no longer think of international action only as the game of war against locusts, but also as a permanent biovigilance, which equitably distributes risks among the players [90]. Stopping the erosion of vigilance thus relies on the perpetuation of a difficult coordination among heterogeneous actors: solitarious desert locusts, the information network that connects the managers, and research projects play a central role in this maintenance over time. These multiple components allow the managers to have more continuity and free themselves from having to act in a crisis mode [9]. While Gay et al. also illustrated the role of funding institutions' awareness as a facilitating factor for cyclic locust plagues, they argued that loss of skilled field agents was of primary concern and their recommendations thus included plague simulation exercises [61]. Most locust response systems are subject to this cyclic loss, but awareness has been building for several years and locust managers are now trying to take better account of these issues. For instance, in the case of the desert locust, CLCPRO has implemented risk management plans including simulation exercises between outbreaks, a monitoring and evaluation plan to enable actors in the system to know in real time and at the country level, the state of equipment, staff or pesticides, and a communication plan (http:/ / www.fao.org/clcpro/fr/, accessed on 10 May 2021). More recently, a financing system designed to address the various levels of desert locust infestations began to be developed [91]. There are also successful examples such as the Australian Plague Locust Commission (APLC) in Australia. The APLC has been funded continuously by four Australian member states from 1974. This funding supports the maintenance of their structures and keeps them prepared to immediately react in the event 
of an alert [92]. We can speculate that this stability is explained both by the fact that the relatively high frequency of Australian plague locust outbreaks helps to maintain the motivation of the actors, and that it concerns a single country that is politically stable and has a high GDP.

These spatio-temporal challenges of governing transient socio-environmental problems are not specific to locusts and can be analyzed using the concept of "temporal misfit" or "temporal-scale mismatch" between biophysical systems and institutions [30,93]. A temporal misfit can be defined as a case in which an institution is formed too early or too late to cause desired ecosystem effects, or if conflicting time frames exist between policy-makers and those of the environment. In the literature, such temporal governance challenges can be found for a diversity of risks and disasters, ranging from epidemics [94] and wildfires [95] to nuclear risk [96]. As illustrated for governing epidemics [94], the dominance of an outbreak narrative can have drawbacks such as marginalizing narratives that emphasize long-term structural, land use, and environmental changes, and local knowledge. The risk of loss of knowledge and expertise has also been observed in the case of nuclear risk [96]. Many nuclear employees and experts who designed, constructed, and currently operate existing nuclear power plants are now approaching retirement. A consequence is the potential loss of a substantial amount of critical nuclear energy knowledge. In response, nuclear organizations conduct knowledge loss risk assessments, evaluate the consequences of the loss of critical knowledge and skills, develop action plans to retain this knowledge, and use this knowledge to improve the skills and competencies of new and existing workers. Knowledge loss may be related to cyclicity, as described for example in bank lending behavior [97]. In this case, the institutional memory hypothesis speculates that cyclicity may be driven by a deterioration in the ability to recognize problems: institutions may tend to forget the lessons they learned as time passes since their last learning experience with the problem. Studies on risk perceptions have shown that personal experience of a natural hazard and trust in authorities has a substantial impact on risk perception. However, perceiving a risk is not sufficient to guarantee that an actor will take action; action depends on motivation, responsibility, and ability to respond [98].

In the case of locusts, these elements question the dominance of an outbreak narrative, the frequency of learning experiences, and the fact that they may be growing increasingly apart in time due to the implementation of effective preventive strategies. A common trap with preventive strategies is that when you are successful in prevention, there seems to be no need for prevention: the perception of the risk disappears, and with it the feeling that investment in prevention systems must be maintained. Bödin argues that the management of such transient environmental problems requires rapid responses, and thus the mobilization of relevant actors organized in ad hoc collaborative networks [79]. In such conditions, studies on collaborative governance have demonstrated that more-centralized networks with specific actors acting as leaders by distributing and coordinating tasks were more favorable [99], if actors already agree on what needs to be done, share inter-personal and inter-organizational trust, and are willing to comply with the identified responses. This of course requires underlying, dense and longer lasting collaborations, even during the absence of locust plagues.

\section{Conclusions: Engaging Social Sciences to Improve Sustainable Locust Management}

Social sciences are a vital component, along with the natural sciences, for effective and sustainable locust management, including decision-making, planning, implementation, and management both during crisis and recession times. In this paper, our objective has been to clarify the role played by social sciences and inspire uptake of the social sciences in locust research and management. We have highlighted the diversity of possible applications and contributions, as well as some of the existing contributions to respond to the main challenges faced by locust managers around the world. We have also pointed out some shortcomings, such as the limited questioning of locust management narratives and underlying epistemologies. Examples of studies on other large-scale and erratic socio- 
environmental problems such as epidemics, hurricanes, and wildfires could shed new light and perspectives on the present and future challenges faced by locust managers. In particular, some long-term environmental and social changes may challenge the way locusts were previously managed. These changes include not only land-use and climate change and rising environmental concerns, but also renewed environmental governance models that include more bottom-up and participative approaches, and increasing calls for social justice [70]. Such changes call for new ways of interacting and living with nature and with locusts. They question the dominant narratives focusing predominantly on technoscientific control, mobilizing war rhetoric or continuing to present locusts as a biblical plague. The social sciences can help take a step towards making salient what we often take for granted such as taking into account only techno-scientific parameters, highlight the impact of variable social aspirations and political divisiveness, and invent the future of sustainable locust management.

Supplementary Materials: The following are available online at https:/ /www.mdpi.com/article/10 .3390/agronomy11050951/s1, Table S1: Detailed categorization of the papers referenced in Figure 1 and graphically illustrated in Figure $2(n=25)$.

Author Contributions: Conceptualization, C.T., J.M.A. and A.C.; validation, J.M.A. and A.C.; writing —original draft preparation, C.T.; writing—review and editing, C.T., J.M.A., M.L. and A.C.; visualization, C.T.; supervision, J.M.A. and A.C.; project administration, A.C.; funding acquisition, A.C. All authors have read and agreed to the published version of the manuscript.

Funding: This research was funded by the Foundation for Food and Agricultural Research, grants no. 593561, by the Global Locust Initiative and by the Swette Center for Sustainable Food Systems.

Acknowledgments: Research reported in this publication is supported by the Foundation for Food \&Agriculture Research, Grant ID: 593561, the Global Locust Initiative and the Swette Center for Sustainable Food Systems at Arizona State University. The content of this publication is solely the responsibility of the authors and does not necessarily represent the official views of the Foundation for Food \&Agriculture Research.

Conflicts of Interest: The authors declare no conflict of interest. Given their role as Guest Editor, Michel Lecoq \& Arianne Cease had no involvement in the peer-review of this article and had no access to information regarding its peer-review.

\section{References}

1. Symmons, P.; Cressman, K. Desert Locust Guidelines 5. Campaign Organization and Execution; Food and Agriculture Organization of the United Nations: Rome, Italy, 2001.

2. Pener, M.P.; Simpson, S.J. Locust Phase Polyphenism: An Update. In Advances in Insect Physiology; Simpson, S.J., Pener, M.P., Eds.; Academic Press: Cambridge, MA, USA, 2009; Volume 36, pp. 1-272.

3. Brader, L.; Djibo, H.; Faye, F.; Ghaout, S.; Lazar, M.; Luzietoso, P.; Babah, M.O. Towards a More Effective Response to Desert Locusts and Their Impacts on Food Security, Livelihoods and Poverty; FAO: Rome, Italia, 2006.

4. de Vreyer, P.; Guilbert, N.; Mesplé-Somps, S. The 1987-89 Locust Plague in Mali: Evidences of the Heterogeneous Impact of Income Shocks on Education Outcomes; No. DT/2012/06, WorkingPapers; DIAL (Développement, Institutions et Mondialisation): Paris, France, 2012; 48p.

5. Belayneh, Y.T. Acridid pest management in the developing world: A challenge to the rural population, a dilemma to the international community. J. Orthopt. Res. 2005, 14, 187-195. [CrossRef]

6. Peveling, R. Environmental conservation and locust control-Possible conflicts and solutions. J. Orthopt. Res. 2001, 10, 171-187. [CrossRef]

7. Everts, J.W.; Ba, L.; Krall, S.; Peveling, R.; Diallo, D.B. Environmental effects of locust control: State of the art and perspectives. In New Strategies in Locust Control; Springer Science and Business Media LLC: Berlin/Heidelberg, Germany, 1997; pp. 331-336.

8. Péloquin, C. Locust swarms and the spatial techno-politics of the French Resistance in World War II. Geoforum 2013, 49, $103-113$. [CrossRef]

9. Doré, A.; Barbier, M. Maintenir la vigilance. Rev. Anthropol. Connaiss. 2015, 9, 189. [CrossRef]

10. Deveson, E.; Martinez, A. Locusts in Southern Settler Societies: Argentine and Australian Experience and Responses, 1880-1940. In Environmental History in the Making; Vaz, E., Joanaz de Melo, C., Costa Pinto, L.M., Eds.; Springer International Publishing: Cham, Switzerland, 2017; Volume 1, pp. 259-286.

11. Uvarov, B.P. A Revision of the Genus Locusta, L. (= Pachytylus, Fieb.), with a New Theory as to the Periodicity and Migrations of Locusts. Bull. Èntomol. Res. 1921, 12, 135-163. [CrossRef] 
12. Uvarov, B. Biological and Ecological Basis of Locust Phases and Their Practical Application. In Proceedings of the 4th International Locust Conference, Cairo, Egypt, 23 April 1936.

13. Showler, A.; Ebbe, M.O.B.; Lecoq, M.; Maeno, K. Early Intervention against Desert Locusts: Current Proactive Approach and the Prospect of Sustainable Outbreak Prevention. Agronomy 2021, 11, 312. [CrossRef]

14. Zhang, L.; Lecoq, M.; Latchininsky, A.; Hunter, D. Locust and Grasshopper Management. Annu. Rev. Èntomol. 2019, 64, 15-34. [CrossRef] [PubMed]

15. Pantenius, C. Towards Better Desert Locust Risk Prevention Systems in the Central Region; FAO: Rome, Italy, 2015; 24p.

16. Magor, J.; Lecoq, M.; Hunter, D. Preventive control and Desert Locust plagues. Crop. Prot. 2008, 27, 1527-1533. [CrossRef]

17. Symmons, P. A Critique of "Preventive Control and Desert Locust Plagues". Crop Prot. 2009, 28, 905-907. [CrossRef]

18. Enserink, M. Can the War on Locusts Be Won? Science 2004, 306, 1880. [CrossRef] [PubMed]

19. Lecoq, M. Desert locust management: From ecology to anthropology. J. Orthopt. Res. 2005, 14, 179-186. [CrossRef]

20. Gomes, I.; Queiroz, A.I.; Alves, D. Iberians against locusts: Fighting cross-border bio-invaders (1898-1947). Hist. Agrar. Rev. Agric. Hist. Rural. 2019, 78, 127-159. [CrossRef]

21. Roy, J. Histoire d'un Siècle de Lutte Anti-Acridienne en Afrique. Contributions de la France; L'Harmattan: Paris, France, 2001.

22. Meynard, C.N.; Lecoq, M.; Chapuis, M.; Piou, C. On the relative role of climate change and management in the current desert locust outbreak in East Africa. Glob. Chang. Biol. 2020, 26, 3753-3755. [CrossRef]

23. Showler, A.T.; Lecoq, M. Incidence and Ramifications of Armed Conflict in Countries with Major Desert Locust Breeding Areas. Agronomy 2021, 11, 114. [CrossRef]

24. Cullen, D.A.; Cease, A.J.; Latchininsky, A.V.; Ayali, A.; Berry, K.; Buhl, J.; De Keyser, R.; Foquet, B.; Hadrich, J.C.; Matheson, T.; et al. Chapter Seven-From Molecules to Management: Mechanisms and Consequences of Locust Phase Polyphenism. In Advances in Insect Physiology; Verlinden, H., Ed.; Academic Press: Cambridge, MA, USA, 2017; Volume 53, pp. $167-285$.

25. Millist, N.; Abdalla, A. Benefit-Cost Analysis of Australian Plague Locust Control Operations for 2010-11; Australian Bureau of Agricultural and Resource Economics and Sciences: Canberra, Australia, 2011; 22p.

26. Magarey, R.D.; Chappell, T.M.; Trexler, C.M.; Pallipparambil, G.R.; Hain, E.F. Social Ecological System Tools for Improving Crop Pest Management. J. Integr. Pest Manag. 2019, 10, 10. [CrossRef]

27. De Marchi, B.; Ravetz, J.R. Risk Management and Governance: A Post-Normal Science Approach. Futures 1999, $31,743-757$. [CrossRef]

28. Dangles, O.; Pérez, V.C. Editorial overview: Devastating locust swarms and pandemics: The same pressing need for sustainability science. Curr. Opin. Insect Sci. 2020, 40. [CrossRef] [PubMed]

29. Berkes, F.; Folke, C. Linking Social and Ecological Systems: Management Practices and Social Mechanisms for Building Resilience; Cambridge University Press: Cambridge, UK, 1998.

30. Cash, D.W.; Adger, W.N.; Berkes, F.; Garden, P.; Lebel, L.; Olsson, P.; Pritchard, L.; Young, O. Scale and Cross-Scale Dynamics: Governance and Information in a Multilevel World. Ecol. Soc. 2006, 11, 8. [CrossRef]

31. Cease, A.J.; Elser, J.J.; Fenichel, E.P.; Hadrich, J.C.; Harrison, J.F.; Robinson, B.E. Living with Locusts: Connecting Soil Nitrogen, Locust Outbreaks, Livelihoods, and Livestock Markets. Bioscience 2015, 65, 551-558. [CrossRef]

32. Balint, P.J.; Stewart, R.E.; Desai, A.; Walters, L.C. Wicked Environmental Problems: Managing Uncertainty and Conflict; Island Press: Washington, DC, USA, 2011.

33. Funtowicz, S.O.; Ravetz, J.R. The Emergence of Post-Normal Science. In Science, Politics and Morality; Springer Science and Business Media LLC: Berlin/Heidelberg, Germany, 1993; pp. 85-123.

34. Lang, D.J.; Wiek, A.; Bergmann, M.; Stauffacher, M.; Martens, P.; Moll, P.; Swilling, M.; Thomas, C.J. Transdisciplinary research in sustainability science: Practice, principles, and challenges. Sustain. Sci. 2012, 7, 25-43. [CrossRef]

35. Palsson, G.; Szerszynski, B.; Sörlin, S.; Marks, J.; Avril, B.; Crumley, C.; Hackmann, H.; Holm, P.; Ingram, J.; Kirman, A.; et al. Reconceptualizing the 'Anthropos' in the Anthropocene: Integrating the social sciences and humanities in global environmental change research. Environ. Sci. Policy 2013, 28, 3-13. [CrossRef]

36. Bennett, N.J.; Roth, R.; Klain, S.C.; Chan, K.; Christie, P.; Clark, D.A.; Cullman, G.; Curran, D.; Durbin, T.J.; Epstein, G.; et al. Conservation social science: Understanding and integrating human dimensions to improve conservation. Biol. Conserv. 2017, 205, 93-108. [CrossRef]

37. Lewis, W.J.; Van Lenteren, J.C.; Phatak, S.C.; Tumlinson, J.H. A total system approach to sustainable pest management. Proc. Natl. Acad. Sci. USA 1997, 94, 12243-12248. [CrossRef]

38. Fox, H.E.; Christian, C.E.; Nordby, J.C.; Pergams, O.R.W.; Peterson, G.D.; Pyke, C.R. Perceived Barriers to Integrating Social Science and Conservation. Conserv. Biol. 2006, 20, 1817-1820. [CrossRef]

39. Büscher, B.; Wolmer, W. Introduction: The Politics of Engagement between Biodiversity Conservation and the Social Sciences. Conserv. Soc. 2007, 5, 1-21.

40. Brosius, J.P. Common ground between anthropology and conservation biology. Conserv. Biol. 2006, 20, 683-685. [CrossRef] [PubMed]

41. Sievanen, L.; Campbell, L.M.; Leslie, H.M. Challenges to Interdisciplinary Research in Ecosystem-Based Management. Conserv. Biol. 2012, 26, 315-323. [CrossRef] [PubMed]

42. Moon, K.; Blackman, D. A Guide to Understanding Social Science Research for Natural Scientists. Conserv. Biol. 2014, 28, 1167-1177. [CrossRef] 
43. Alexander, S.M.; Armitage, D. A Social Relational Network Perspective for MPA Science. Conserv. Lett. 2015, 8, 1-13. [CrossRef]

44. Cox, M. A basic guide for empirical environmental social science. Ecol. Soc. 2015, 20, 20. [CrossRef]

45. Robbins, P. Critical Introductions to Geography. In Political Ecology: A Critical Introduction; Blackwell Publishing: Oxford, UK, 2004.

46. Rose, D.B.; Van Dooren, T.; Chrulew, M.; Cooke, S.; Kearnes, M.; O'Gorman, E. Thinking Through the Environment, Unsettling the Humanities. Environ. Humanit. 2012, 1, 1-5. [CrossRef]

47. Abou-Ali, H.; Belhaj, M. Cost Benefit Analysis of Desert Locusts' Control: A Multicountry Perspective; Working paper 0801; Economic Research Forum: Giza, Egypt, 2008.

48. Lockwood, J.A.; Showler, A.; Latchininsky, A.V. Can we make locust and grasshopper management sustainable? J. Orthopt. Res. 2001, 10, 315-329. [CrossRef]

49. Gaspar, R.; Yan, Z.; Domingos, S. Extreme natural and man-made events and human adaptive responses mediated by information and communication technologies' use: A systematic literature review. Technol. Forecast. Soc. Chang. 2019, 145, 125-135. [CrossRef]

50. Künckel D’Herculais, J. Invasion des Acridiens, Vulgo Sauterelles, en Algérie (1893-1905); Imprimerie Administrative et Commerciale Giralt, Gouvernement Général de l'Algérie: Alger, Algeria, 1905.

51. Peloquin, C. Unruly Nature and Technological Authority: Governing Locust Swarms in the Sahel. Ph.D. Thesis, University of Arizona, Tuscon, AZ, USA, 2014.

52. Byrne, A.T.; Hadrich, J.C.; Robinson, B.E.; Han, G. A factor-income approach to estimating grassland protection subsidy payments to livestock herders in Inner Mongolia, China. Land Use Policy 2020, 91, 104352. [CrossRef]

53. Deveson, E.D. The Search for a Solution to Australian Locust Outbreaks: How Developments in Ecology and Government Responses Influenced Scientific Research. Hist. Rec. Aust. Sci. 2011, 22, 1-31. [CrossRef]

54. Liu, J.; Hull, V.; Batistella, M.; DeFries, R.; Dietz, T.; Fu, F.; Hertel, T.W.; Izaurralde, R.C.; Lambin, E.F.; Li, S.; et al. Framing Sustainability in a Telecoupled World. Ecol. Soc. 2013, 18, 18. [CrossRef]

55. Cumming, G.S.; Cumming, D.H.M.; Redman, C.L. Scale Mismatches in Social-Ecological Systems: Causes, Consequences, and Solutions. Ecol. Soc. 2006, 11, 11. [CrossRef]

56. Le Gall, M.; Overson, R.; Cease, A. A Global Review on Locusts (Orthoptera: Acrididae) and Their Interactions with Livestock Grazing Practices. Front. Ecol. Evol. 2019, 7, 7. [CrossRef]

57. Word, M.L.; Hall, S.J.; Robinson, B.E.; Manneh, B.; Beye, A.; Cease, A.J. Soil-targeted interventions could alleviate locust and grasshopper pest pressure in West Africa. Sci. Total. Environ. 2019, 663, 632-643. [CrossRef] [PubMed]

58. Skaf, R. Le Criquet Marocain au Proche-Orient et sa grégarisation sous l'influence de l'homme. Bull. Soc. Ecol. 1972, 3, $247-325$.

59. Benfekih, L.; Chara, B.; Doumandji-Mitiche, B. Influence of Anthropogenic Impact on the Habitats and Swarming Risks of Dociostaurus maroccanus and Locusta migratoria (Orthoptera, Acrididae) in the Algerian Sahara and the Semiarid Zone. J. Orthopt. Res. 2002, 11, 243-250. [CrossRef]

60. Gay, P.; Lecoq, M.; Piou, C. The limitations of locust preventive management faced with spatial uncertainty: Exploration with a multi-agent model. Pest Manag. Sci. 2020, 76, 1094-1102. [CrossRef]

61. Gay, P.-E.; Lecoq, M.; Piou, C. Improving preventive locust management: Insights from a multi-agent model. Pest Manag. Sci. 2018, 74, 46-58. [CrossRef]

62. Toleubayev, K.; Jansen, K.; Van Huis, A. Locust Control in Transition: The Loss and Reinvention of Collective Action in Post-Soviet Kazakhstan. Ecol. Soc. 2007, 12. Available online: http://www.ecologyandsociety.org/vol12/iss2/art38/ (accessed on 10 May 2021).

63. Joffe, S. Economic and Policy Issues in Desert Locust Management: A Preliminary Analysis; FAO: Rome, Italy, 1998.

64. Krall, S. Desert Locusts in Africa: A Disaster? Disasters 1995, 19, 1-7. [CrossRef] [PubMed]

65. Joffe, S.R. Desert Locust Management; The World Bank: Washington, DC, USA, 1995.

66. Hardeweg, B. A Conceptual Framework for Economic Evaluation of Desert Locust Management Interventions; Institute of Horticultural Economics: Hannover, Germany, 2001.

67. Emana, B. Socio-Economics of Desert Locust Control in Sudan. A Micro Level Case Study. Final Draft Report; Food and Agriculture Organization of the United Nations: Rome, Italy, 2002.

68. De Groote, H.; Douro-Kpindou, O.-K.; Ouambama, Z.; Gbongboui, C.; Müller, D.; Attignon, S.; Lomer, C. Assessing the Feasibility of Biological Control of Locusts and Grasshoppers in West Africa: Incorporating the Farmers' Perspective. Agric. Hum. Values 2001, 18, 413-428. [CrossRef]

69. Manthey, S. Curse of the Good Rains the Long-Run Impacts of Locust Infestations. Evidence from the 1986-89 Locust Plague in the Sahel; Lund University: Lund, Sweden, 2020; 77p.

70. Lockwood, J.; Sardo, M. A Swarm of Injustice: A Sociopolitical Framework for Global Justice in the Management of the Desert Locust. Agronomy 2021, 11, 386. [CrossRef]

71. Lockwood, J.A. An Excerpt of Locust: The Devastating Rise and Mysterious Disappearance of the Insect that Shaped the American Frontier. Am. Èntomol. 2004, 50, 222-227. [CrossRef]

72. Catenaccio, C. (Senasa, Buenos Aires, Argentina) South American Locusts: A Crisis That Creates Opportunities. Personal communication, 2018.

73. Lecoq, M. Desert Locust Threat to Agricultural Development and Food Security and FAO/International Role in Its Control. Arab. J. Plant Prot. 2003, 21, 188-193. 
74. Desanges, J. Témoignages antiques sur le fléau acridien. Pub. Acad. Inscript. Belles Lett. 2006, 17, $221-235$.

75. Buj, A. Nature et environnement. International experimentation and control of the locust plague: Africa in the first half of the 20th century. In Les Sciences Hors d'Occident au 20ème Siècle; Waast, R., Chatelin, Y., Bonneuil, C., Eds.; Orstom: Paris, France, 1995; pp. 93-105.

76. Uvarov, B.P. Locust as a World Problem; Commission Française d'Études des Calamités with the Support of Union Internationale de Secours: Paris, France, 1937; pp. 376-382.

77. Lecoq, M. Projet de Restructuration des Organismes Chargés de la Surveillance et de la Lutte Contre le Criquet Pèlerin en Région Occidentale. Justifications et Propositions; FAO/AGP-P; Food and Agriculture Organization of the United Nations: Rome, Italy, 1999.

78. FAO. Accord Portant Création d'Une Commission de Lutte Contre le Criquet Pèlerin dans la Région Occidentale, en Vertu de l'Article XIV de l'Acte Constitutif de la FAO; Food and Agriculture Organization of the United Nations: Rome, Italy, 2000.

79. Bodin, Ö. Collaborative environmental governance: Achieving collective action in social-ecological systems. Science 2017, 357, eaan1114. [CrossRef] [PubMed]

80. Damtew, E.; Van Mierlo, B.; Lie, R.; Struik, P.; Leeuwis, C.; Lemaga, B.; Smart, C. Governing a Collective Bad: Social Learning in the Management of Crop Diseases. Syst. Pract. Action Res. 2020, 33, 111-134. [CrossRef]

81. Graham, S.; Metcalf, A.L.; Gill, N.; Niemiec, R.; Moreno, C.; Bach, T.; Ikutegbe, V.; Hallstrom, L.; Ma, Z.; Lubeck, A. Opportunities for better use of collective action theory in research and governance for invasive species management. Conserv. Biol. 2018, 33, 275-287. [CrossRef]

82. Ostrom, E. Governing the Commons; Cambridge University Press: Cambridge, UK, 1990.

83. Thomson, A.; Miers, H. Assessment of the Socio-Economic Impact of Desert Locust and Their Control; UK Department for International Development: London, UK, 2002; p. 37.

84. Food and agriculture organization of the United Nations. Programme Evaluation of The Emergency Prevention System for Transboundary Animal and Plant Pests and Diseases (EMPRES): Desert Locust; Food and Agriculture Organization of the United Nations: Rome, Italy, 2002.

85. Berkes, F. From Community-Based Resource Management to Complex Systems: The Scale Issue and Marine Commons. Ecol. Soc. 2006, 11, 11. [CrossRef]

86. Fleischman, F.D.; Ban, N.C.; Evans, L.S.; Epstein, G.; Garcia-Lopez, G.; Villamayor-Tomas, S. Governing Large-Scale SocialEcological Systems: Lessons from Five Cases. Int. J. Commons 2014, 8, 428-456. [CrossRef]

87. Young, O.R. The Institutional Dimensions of Environmental Change: Fit, Interplay, and Scale; MIT Press: London, UK, 2002.

88. Lecoq, M. Lecoq, M. Le Criquet pèlerin. Enseignements de la dernière invasion et perspectives offertes par la biomodélisation. In La Lutte Anti-Acridienne; AUPELF-UREF, John Libbey Eurotext: Paris, France, 1991; pp. 71-98.

89. Medina, H.; Cease, A.; Trumper, E. The Resurgence of the South American Locust (Schistocerca cancellata). Metaleptea 2017, 37, $17-21$.

90. Doré, A.; Barbier, M.; Lecoq, M.; Babah, M.A.O. Prévention des invasions de criquets pèlerins: Analyse socio-technique d'un dispositif de gestion du risque. Cah. Agric. 2008, 17, 457-464.

91. Deshormes, A. Institutional Study to Enhance the Roles and Responsibilities of the Desert Locust Control Commissions Established under Article XIV. Financial Governance. Final Report; Food and Agriculture Organization of the United Nations: Rome, Italy, 2011.

92. Adriaansen, C.; Woodman, J.D.; Deveson, E.D.; Drake, V.A. The Australian Plague Locust—Risk and Response. In Biological and Environmental Hazards, Risks, and Disasters; Elsevier: Amsterdam, The Netherlands, 2016; pp. 67-86.

93. Rosenschöld, J.M.A.; Honkela, N.; Hukkinen, J.I. Addressing the temporal fit of institutions: The regulation of endocrinedisrupting chemicals in Europe. Ecol. Soc. 2014, 19, 19. [CrossRef]

94. Leach, M.; Scoones, I.; Stirling, A. Governing epidemics in an age of complexity: Narratives, politics and pathways to sustainability. Glob. Environ. Chang. 2010, 20, 369-377. [CrossRef]

95. Boin, A.; 'T Hart, P. Organising for Effective Emergency Management: Lessons from Research 1. Aust. J. Public Adm. 2010, 69, 357-371. [CrossRef]

96. Boyles, J.E.; Kirschnick, F.; Kosilov, A.; Yanev, Y.; Mazour, T. Risk Management of Knowledge Loss in Nuclear Industry Organisations. Int. J. Nucl. Knowl. Manag. 2009, 3, 125-136. [CrossRef]

97. Berger, A.N.; Udell, G.F. The Institutional Memory Hypothesis and the Procyclicality of Bank Lending Behavior. J. Financ. Intermed. 2004, 13, 458-495. [CrossRef]

98. Wachinger, G.; Renn, O.; Begg, C.; Kuhlicke, C. The Risk Perception Paradox-Implications for Governance and Communication of Natural Hazards. Risk Anal. 2012, 33, 1049-1065. [CrossRef] [PubMed]

99. Lubell, M.; Jasny, L.; Hastings, A. Network Governance for Invasive Species Management. Conserv. Lett. 2016, 10, 699-707. [CrossRef] 